\title{
Randomised controlled trial of inhaled corticosteroids in patients with chronic obstructive pulmonary disease
}

\author{
Jean Bourbeau, Michel Y Rouleau, Serge Boucher
}

\begin{abstract}
Background-Inhaled corticosteroids are known to be beneficial for patients with asthma, but their role in treating patients with stable chronic obstructive pulmonary disease (COPD) remains controversial. A study was undertaken to determine whether inhaled corticosteroids are of functional benefit in patients who did not show improvement with a trial of oral corticosteroids.

Methods-In phase I patients with stable COPD were given a two week course of oral placebo followed by two weeks of prednisone $40 \mathrm{mg}$ per day in a single blind manner to distinguish between responders and non-responders to oral corticosteroids. In phase II a double blind, randomised, parallel group trial of inhaled budesonide $1600 \mu \mathrm{g}$ per day versus placebo was carried out in 79 nonresponders to oral corticosteroids. The primary outcome measure was forced expiratory volume in one second $\left(\mathrm{FEV}_{1}\right)$, and secondary outcome measures were exercise capacity, dyspnoea with exertion, quality of life, peak expiration flow rate, and respiratory symptoms.
\end{abstract}

Results-Randomisation allocated 39 subjects to inhaled corticosteroids and 40 to placebo. There was no difference in the change in $\mathrm{FEV}_{1}$ from baseline between the treatment and placebo groups; mean difference $-12 \mathrm{ml}(95 \% \mathrm{CI}-88$ to 63$)$ at three months and $-4 \mathrm{ml}(95 \% \mathrm{CI}-95$ to 87$)$ at six months. The proportion of patients with a $15 \%$ or greater improvement was no higher among those receiving inhaled corticosteroids than in the placebo group at any of the follow up visits. Changes in secondary outcomes were also no different. Conclusions-Inhaled corticosteroids, even at high doses, were of no physiological or functional benefit in these patients with advanced COPD.

(Thorax 1998;53:477-482)

Keywords: inhaled corticosteroids; chronic obstructive pulmonary disease; drug therapy

Corticosteroids are one of the many therapeutic modalities that pose a clinical dilemma in the treatment of stable chronic obstructive pulmonary disease (COPD). Oral corticosteroids are recommended in patients with COPD who remain symptomatic while receiving regular bronchodilator therapy. In a recent meta- analysis ${ }^{1}$ it was estimated that the percentage of patients with stable COPD who benefit from oral corticosteroids was only $10 \%$ (95\% CI 2 to 18) more than similar patients who receive placebo. Thus, the percentage of patients who will benefit from oral corticosteroids appears to be modest, and the potential for side effects when taken regularly represents a major problem.

Inhaled corticosteroids, which have substantially fewer and less severe systemic side effects, have gained wide acceptance in the treatment of patients with airway disease with little regard for the underlying disease process. In the few studies where patients with COPD have been selected according to a significant response to oral corticosteroids, ${ }^{23}$ the proportion of patients and the size of the effect have been consistently less in patients receiving inhaled corticosteroids than in those receiving oral corticosteroids. In other studies ${ }^{4-11}$ carried out in patients not previously selected for their response to oral corticosteroids, the results have been conflicting with regard to the physiological or functional efficacy of an inhaled corticosteroid. Some studies have included patients with asthma ${ }^{10}$ or younger patients with preclinical COPD. ${ }^{11}$ Although the results of a study in patients with selected preclinical COPD are valid and may be of importance in exploring the pathogenesis of the disease, their clinical relevance is less certain since most patients with COPD come to medical attention with moderate to advanced disease. No controlled study has been carried out using high doses of inhaled corticosteroid to evaluate physiological and functional benefits in the large subgroup of patients who do not improve significantly with oral corticosteroids.

We report a double blind, randomised, placebo controlled trial in patients with stable COPD, who remained symptomatic while receiving treatment with regular bronchodilators and who had not shown significant improvement during a trial of oral corticosteroids, to determine whether forced expiratory volume in one second $\left(\mathrm{FEV}_{1}\right)$ could be improved with high dose inhaled corticosteroids taken regularly for at least six months. Secondary outcomes included exercise capacity, dyspnoea with exercise, quality of life, peak expiratory flow rate (PEFR), and usual respiratory symptoms.

\section{Methods}

The study was conducted in a pulmonary outpatient clinic of a university affiliated hospital. The study protocol was approved by the 
institutional ethics committee and written informed consent was signed by all participants.

The study was conducted in two phases. Phase I of the study was designed to distinguish between patients with COPD who did not improve with oral corticosteroids and those who did improve with this therapy. Phase II evaluated the efficacy of inhaled corticosteroids in patients with COPD who did not improve with oral steroids during phase I.

PHASE I: IDENTIFICATION OF NON-RESPONDERS TO ORAL CORTICOSTEROIDS

Selection criteria

To be eligible for the study the patients had to meet the following criteria: (1) age 40 years old or older; (2) smokers or ex-smokers; (3) no history of allergic asthma during childhood or as an adult; (4) absence of an exacerbation in respiratory symptoms during the two months prior to the study; (5) pre-bronchodilator $\mathrm{FEV}_{1}$ less than $65 \%$ of predicted ${ }^{12}$ and $\mathrm{FEV}_{1} /$ forced vital capacity (FVC) less than 0.65 ; (6) post-bronchodilator $\mathrm{FEV}_{1}$ less than $80 \%$; (7) regular treatment with at least one bronchodilator; (8) no inhaled corticosteroids in the previous month or oral corticosteroids in the previous two months; (9) absence of any other active lung disease; (10) absence of diabetes, active peptic ulcer disease, uncontrolled high blood pressure, or congestive heart failure; and (11) absence of disease other than COPD that might interfere with quality of life.

Treatment with oral corticosteroids

All patients were assessed in a single blind manner with a two week course of oral placebo followed by two weeks of prednisone $40 \mathrm{mg}$ daily. The prednisone was subsequently tapered and discontinued completely during the third week. A response to oral corticosteroids was defined in terms of changes in the pre-bronchodilator $\mathrm{FEV}_{1}$ as measured at each visit. Patient in whom the $\mathrm{FEV}_{1}$ had not improved by at least $15 \%$ and $200 \mathrm{ml}$ compared with the baseline or placebo values after the two week course of oral prednisone were defined as oral corticosteroid nonresponders.

PHASE II: TREATMENT WITH INHALED

CORTICOSTEROID OR PLACEBO

Study design and treatment

In those patients with COPD who did not improve with oral corticosteroids a double blind, randomised, parallel group trial of high dose inhaled budesonide versus placebo was carried out. Patients were randomly assigned to receive budesonide or placebo from a Turbohaler, two inhalations of $400 \mu \mathrm{g}$ twice daily for six months. While originally the treatment period was to last 12 months, insufficient numbers of patients were able to remain in the trial for this length of time and the power was therefore insufficient to detect significant treatment differences at 12 months. Randomisation was carried out in blocks of four patients to ensure similar numbers of patients in each treatment group. Identification of individual treatment assignments was only possible in case of emergency by breaking the sealed envelope kept by the investigator. The envelopes had to be kept with the case record forms and be returned unbroken at the end of the study. Patients were instructed in the use of the inhaler and medications and proper technique was reinforced at each visit. All medication for the well being of the patients was permitted except inhaled corticosteroids other than budesonide. In case of treatment failure, rescue medication with $\beta_{2}$ agonists or systemic steroids was available. Patients who developed an exacerbation of their disease and required systemic steroids were allowed to continue in the trial and their regular visit schedule was resumed after their condition had stabilised. Ophthalmological, otic, and/or dermatological corticosteroid preparations were permitted. A concerted effort was made to keep all concurrent medications as constant as possible during the study and these were recorded in the patient diaries.

\section{Evaluation and follow up}

The following baseline measurements were made before the start of the study: (1) pertinent medical history; (2) validated French version of the ATS-DLD-78 questionnaire ${ }^{13}$; (3) physical examination; (4) chest radiography; (5) pre- and post-bronchodilator $\mathrm{FEV}_{1}$ and FVC; (6) six minute walking test ${ }^{14}{ }^{15}$ with estimation of the degree of dyspnoea on exertion as assessed by a visual analogue scale (VAS); (7) quality of life questionnaire ${ }^{16}$; (8) complete blood counts; (9) serum theophylline level; (10) plasma cortisol level. Follow up visits were made at one, three, and six months. Pre- and post-bronchodilator $\mathrm{FEV}_{1}$ and FVC, pre-bronchodilator six minute walking test, dyspnoea with exercise, and quality of life questionnaires were administered by the same research assistant at each visit. Morning and evening PEFR and symptom scores (shortness of breath and cough) were recorded daily in a diary for three months and then weekly. Patients could be withdrawn from the study at any time at the discretion of the investigator or at their own request. Patient withdrawal was classified as being due to non-compliance to the study protocol, pulmonary problems, serious adverse events, or refusal of further participation. The reason for withdrawal was specified on a study termination form provided.

\section{Spirometric tests}

Spirometric tests were carried out in all patients at each visit according to ATS guidelines $^{17}$ with a calibrated rolling seal spirometer. $\mathrm{FEV}_{1}$ and FVC were measured before and 20-40 minutes after four single inhalations of $250 \mu \mathrm{g}$ terbutaline sulphate administered through a $750 \mathrm{ml}$ spacer device (Nebuhaler). At least three reproducible values (that is, with less than $5 \%$ difference between measurements) were obtained and the highest value was used in the analysis. Efforts were made to conduct these tests at the same time of the day at each visit. Whenever possible inhaled bronchodilators were not to have been taken 
Table 1 Mean (SD) characteristics of the oral steroid responders and oral steroid non-responders

\begin{tabular}{lll}
\hline Characteristics & $\begin{array}{l}\text { Oral steroid } \\
\text { responder }\end{array}$ & $\begin{array}{l}\text { Oral steroid } \\
\text { non-responder }\end{array}$ \\
\hline No. of patients & 17 & 79 \\
Age (years) & $69(7)$ & $66(8)$ \\
Pre-BD FEV 1 (1) & $0.98(0.35)$ & $0.93(0.32)$ \\
Post-BD FEV $_{1}(\%$ improvement) & & \\
$\quad$ Baseline & $29(28)$ & $15(13)$ \\
$\quad$ After 2 weeks placebo & $15(19)$ & $14(15)$ \\
Daily PEFR variation $(\%)$ & $11(8)$ & $12(7)$ \\
Eosinophil count $\left(\times 10^{9} / 1\right)$ & $0.4(0.4)$ & $0.4(2.2)$ \\
$\geqslant 1$ allergy positive skin test $(\%)$ & 6 & 6 \\
\hline
\end{tabular}

six hours before the spirometric tests but theophylline could be maintained on a regular basis.

\section{Six minute walking test and dyspnoea after} exercise

A standardised six minute walking test ${ }^{15}$ followed by an evaluation of dyspnoea was carried out in all patients at each visit. The patients were instructed to walk from end to end over 30 metres of an enclosed corridor, covering as much ground as they could during the allotted time. Written instructions were given to the patient before the test. The examiner walked slowly behind the patient for the duration of the test and only spoke to encourage the patient at predetermined times. When the full six minutes had elapsed the patient stopped and the distance completed was added up. In addition, the patients were asked to indicate their level of dyspnoea immediately after the walk test using a $10 \mathrm{~cm}$ visual analogue scale anchored by the terms "extremely short of breath" (0) and "no shortness of breath" (10)

Quality of life questionnaire

The Chronic Respiratory Questionnaire $(\mathrm{CRQ})^{16}$ was administered to all patients at each visit. This questionnaire consists of 20 items aggregated into four dimensions: dyspnoea, fatigue, emotional function, and mastery or a feeling of control over one's disease. Dyspnoea is measured by asking subjects to specify five important and frequent daily activities

Table 2 Characteristics of the study patients with COPD who failed to improve their FEV, with oral corticosteroids*

\begin{tabular}{|c|c|c|}
\hline Characteristic & Budesonide & Placebo \\
\hline No. of patients & 39 & 40 \\
\hline Male/female & $33 / 6$ & $29 / 11$ \\
\hline Age (years) & $66(8)$ & $66(8)$ \\
\hline Smoking (pack years) & $52(27)$ & $50(28)$ \\
\hline Current smoker $(\%)$ & 33 & 45 \\
\hline \multicolumn{3}{|l|}{ Medication at entry (\%) } \\
\hline Theophylline & 64 & 75 \\
\hline Ipratropium bromide & 56 & 45 \\
\hline$\beta_{2}$ agonist (inhaled) & 97 & 100 \\
\hline \multicolumn{3}{|l|}{ Lung function at baseline $e^{\star \star}$} \\
\hline Pre-BD FVC (1) & $2.27(0.64)$ & $2.41(0.74)$ \\
\hline Pre-BD FEV 1 (l) & $0.91(0.33)$ & $0.95(0.30)$ \\
\hline Pre-BD FEV (\% predicted) & $36(12)$ & $37(10)$ \\
\hline Post-BD FEV $1 \%$ predicted) & $43(14)$ & $43(11)$ \\
\hline \multicolumn{3}{|l|}{ Post-BD improvement in $\mathrm{FEV}_{1}$} \\
\hline Absolute change (1) & $0.12(0.11)$ & $0.12(0.12)$ \\
\hline$\%$ predicted $(\%)$ & $5.4(4.7)$ & $4.3(4.8)$ \\
\hline \multicolumn{3}{|l|}{ At randomisation } \\
\hline Pre-BD FEV 1 (1) & $0.94(0.35)$ & $0.97(0.26)$ \\
\hline
\end{tabular}

*Values presented are mean (SD) except for sex, medication at entry, and current smoker.

$\star \star$ Prior to oral corticosteroids. during which they experience shortness of breath. The intensity of dyspnoea experienced doing the five activities was measured serially using a seven point Likert scale (extremely short of breath; very short of breath; quite a bit short of breath; moderate shortness of breath; some shortness of breath; a little shortness of breath, not at all short of breath). The same five activities, identified at first administration of the questionnaire, were used for all subsequent administrations.

\section{Home assessment}

Patients were provided with a daily diary and a mini-Wright peak flow meter to measure PEFR. The highest of three values taken in the morning and 12 hours later in the evening before any medication was recorded in the diary. Similarly, severity of symptoms was recorded for the previous 12 hour periods. Symptoms to be considered in determining a daily symptom score were shortness of breath, chest discomfort, and cough. Scoring was from 0 to $3(0=$ no symptoms; $1=$ awareness of symptoms and/or signs which are easily tolerated; 2 = some discomfort or symptoms causing interference with activities of daily living; 3 = incapacitating symptoms or inability to work or carry out usual activities). Recording frequency was daily during the screening period and for the first 13 weeks of treatment, and thereafter once a week until the end of the study.

\section{STATISTICAL ANALYSIS}

It was estimated that 80 patients providing complete data would be required to give the study a power of $80 \%$ to detect a mean difference in $\mathrm{FEV}_{1}$ of $200 \mathrm{ml}$ between the two groups, assuming that significance would be declared at the two sided 5\% level. The assumption inherent in the power calculation to detect a difference of $200 \mathrm{ml}$ is based on what is considered to be minimal significant difference, week to week changes in $\mathrm{FEV}_{1}$ of $\geqslant 20 \%{ }^{18}$ The primary end point (change in $\mathrm{FEV}_{1}$ ) was first assessed within groups from baseline and between treatment groups. The proportion of patients with $15 \%$ or greater improvement in $\mathrm{FEV}_{1}$ was determined at each visit in each group and compared. Similarly, secondary end points were assessed within groups from baseline and between treatment groups. For the diary data variables, PEFR and symptoms prior to week 13 of treatment the mean value from the last 14 days before each

Table 3 Treatment withdrawal according to treatment group and reason for withdrawal

\begin{tabular}{llc}
\hline & $\begin{array}{c}\text { Budesonide } \\
(n=39)\end{array}$ & $\begin{array}{c}\text { Placebo } \\
(n=40)\end{array}$ \\
\hline Patients who did not complete the study & 1 & 6 \\
3 months & 3 & 10 \\
$\quad$ months & 1 & 2 \\
$\begin{array}{l}\text { Reason for withdrawal } \\
\quad \text { Worsening of respiratory condition }\end{array}$ & 1 & 1 \\
$\quad$ Non-compliance & 1 & \\
$\quad \begin{array}{l}\text { Medical event (concomitent } \\
\text { morbidity) }\end{array}$ & 0 & 1 \\
$\quad$ Unwillingness to continue & 1 & 6 \\
\hline
\end{tabular}

Values presented are numbers of patients. 
Table 4 FEV ${ }_{1}^{\star}$ response after 3 and 6 months of budesonide or placebo

\begin{tabular}{|c|c|c|c|c|c|}
\hline \multirow{2}{*}{$\begin{array}{l}\text { Study period } \\
\text { (months) }\end{array}$} & \multicolumn{2}{|l|}{$F E V_{1}$ changet $(\mathrm{ml})$} & \multirow{2}{*}{$\begin{array}{l}\text { Treatment differencet } \\
\text { Budesonide-placebo }(\mathrm{ml})\end{array}$} & \multicolumn{2}{|c|}{$\begin{array}{l}\text { No. (\%) of patients with } \geqslant 15 \% \text { in } \\
\text { change in FEV }\end{array}$} \\
\hline & Budesonide & Placebo & & Budesonide & Placebo \\
\hline $0-3$ & $\begin{array}{l}\mathrm{n}=38 \\
-13(-59 \text { to } 33)\end{array}$ & $\begin{array}{l}n=34 \\
-1(-65 \text { to } 62)\end{array}$ & $-12(-88$ to 63$)$ & $\begin{array}{l}\mathrm{n}=38 \\
4(11)\end{array}$ & $\begin{array}{l}\mathrm{n}=34 \\
7(20)\end{array}$ \\
\hline $0-6$ & $\begin{array}{l}\mathrm{n}=36 \\
8(-51 \text { to } 68)\end{array}$ & $\begin{array}{l}\mathrm{n}=30 \\
12(-61 \text { to } 85)\end{array}$ & $-4(-95$ to 87$)$ & $\begin{array}{l}\mathrm{n}=36 \\
6(17)\end{array}$ & $\begin{array}{l}\mathrm{n}=30 \\
8(27)\end{array}$ \\
\hline
\end{tabular}

$\star$ Values are pre-bronchodilator $\mathrm{FEV}_{1}$ responses.

tValues are the means with $95 \% \mathrm{CI}$ in parentheses for $\mathrm{FEV}_{1}$ change from baseline and treatment difference.

visit was used for analysis. Thereafter, since steady state was assumed, the mean value for all variable diary data prior to the visit was used. All the analyses were performed on an intention-to-treat basis, meaning that all patients randomised to treatment were included in the analysis, regardless of protocol violations, and including those who had to be withdrawn up to the point of withdrawal. The Wilcoxon signed rank test was first used to test the significance of changes from baseline to treatment within groups, while the Wilcoxon rank sum test was used to test differences between budesonide and placebo treatments. For all tests of significance two tailed alternatives were considered. We present parametric tests and their $95 \%$ confidence intervals which are more self explanatory since parametric tests ( $t$ tests) yielded similar results to nonparametric tests. The data were analysed with SAS version $6.0 .^{19}$

\section{Results}

STUDY PATIENTS

One hundred and forty patients with COPD completed phase I of the study. Of these, 19 $(13.5 \%)$ were defined as oral steroid responders and $121(86.5 \%)$ as oral steroid nonresponders. Seventy nine patients who did not show a significant response to oral corticosteroids (phase I) participated in the randomised trial (phase II), 39 in the inhaled corticosteroid group and 40 in the placebo group. In the group of oral steroid responders the mean improvement in $\mathrm{FEV}_{1}$ after oral corticosteroid therapy was $38 \%$ and $376 \mathrm{ml}$. In the group of oral steroid non-responders $\mathrm{FEV}_{1}$ was basically unchanged after oral corticosteroid therapy in both groups. Age, pre-bronchodilator $\mathrm{FEV}_{1}$, daily PEFR variation, eosinophil count, and atopy were similar, as shown in table 1 . The $\mathrm{FEV}_{1}$ response to treatment with a bronchodilator was higher in the group of oral steroid responders at baseline, but was no different when repeated after a single blind two week course of oral placebo.

The demographic, clinical, and lung function characteristics of the non-responders to oral steroids are shown in table 2. Patients in the two treatment groups (inhaled corticosteroid versus placebo) were similar except that there were more women and current smokers in the placebo group than in the budesonide group. $\mathrm{FEV}_{1}$ was unchanged after oral corticosteroid treatment in both groups.

\section{WITHDRAWALS}

The number of subjects completing the study and the reasons for withdrawal of patients according to treatment group are shown in table 3. Seven patients had withdrawn from the study after three months and 13 had withdrawn after six months. No group differences were observed among the reasons for withdrawal, such as worsening of respiratory conditions, non-compliance, or concomitant morbidity. Seven patients, one in the budesonide group and six in the placebo group, had withdrawn for reasons not related to respiratory problems but unwillingness to continue-for example, duration of the study, inconvenience of travelling during winter season.

Table 5 Secondary outcomes in COPD patients 3 and 6 months after an inhaled corticosteroid or placebo

\begin{tabular}{|c|c|c|c|c|c|c|c|c|}
\hline \multirow[b]{2}{*}{ Outcome measure } & \multicolumn{2}{|c|}{$\begin{array}{l}\text { Baseline* (after } \\
\text { prednisone) }\end{array}$} & \multicolumn{2}{|c|}{ At 3 months change from baselinet } & \multirow[b]{2}{*}{$\begin{array}{l}\text { Treatment } \\
\text { differencet }\end{array}$} & \multicolumn{2}{|c|}{ At 6 months change from baselinet } & \multirow[b]{2}{*}{$\begin{array}{l}\text { Treatment } \\
\text { differencet }\end{array}$} \\
\hline & $\begin{array}{l}\text { Budesonide } \\
(n=39)\end{array}$ & $\begin{array}{l}\text { Placebo } \\
(n=40)\end{array}$ & $\begin{array}{l}\text { Budesonide } \\
(n=38)\end{array}$ & $\begin{array}{l}\text { Placebo } \\
(n=34)\end{array}$ & & $\begin{array}{l}\text { Budesonide } \\
(n=36)\end{array}$ & $\begin{array}{l}\text { Placebo } \\
(n=30)\end{array}$ & \\
\hline \multicolumn{9}{|l|}{ Exercise capacity: } \\
\hline 6-min walking test $\ddagger(\mathrm{m})$ & $311(61)$ & $272(59)$ & $\begin{array}{l}-22 \\
(-35 \text { to }-8)\end{array}$ & $\begin{array}{l}-6 \\
(-21 \text { to } 8)\end{array}$ & $\begin{array}{l}-16 \\
(-35 \text { to } 4)\end{array}$ & $\begin{array}{l}-15 \\
(-26 \text { to }-3)\end{array}$ & $\begin{array}{l}13 \\
(-1.0 \text { to } 27)\end{array}$ & $\begin{array}{l}-28 \\
(-45 \text { to }-10)\end{array}$ \\
\hline $\begin{array}{l}\text { Dyspnoea with exertion } \S \\
(\mathrm{m})\end{array}$ & $5.1(1.7)$ & $5.6(1.9)$ & $\begin{array}{l}0.8 \\
(0 \text { to } 1.6)\end{array}$ & $\begin{array}{l}1.0 \\
(0.3 \text { to } 1.8)\end{array}$ & $\begin{array}{l}-0.2 \\
(-1.3 \text { to } 0.8)\end{array}$ & $\begin{array}{l}0.7 \\
(-0.1 \text { to } 1.5)\end{array}$ & $\begin{array}{l}0.6 \\
(-0.1 \text { to } 1.4)\end{array}$ & $\begin{array}{l}0.1 \\
(-1.0 \text { to } 1.1)\end{array}$ \\
\hline \multicolumn{9}{|l|}{ Quality of life $\|$ : } \\
\hline Dyspnoea & $19.9(6.2)$ & $19.5(5.8)$ & $\begin{array}{l}-1.7 \\
(-3.0 \text { to } 0.5)\end{array}$ & $\begin{array}{l}-0.8 \\
(-3.7 \text { to } 2.2)\end{array}$ & $\begin{array}{l}-0.9 \\
(-4.4 \text { to } 2.5)\end{array}$ & $\begin{array}{l}-1.8 \\
(-3.9 \text { to } 0.2)\end{array}$ & $\begin{array}{l}-0.5 \\
(-2.3 \text { to }-1.3)\end{array}$ & $\begin{array}{l}-1.3 \\
(-4.1 \text { to } 1.5)\end{array}$ \\
\hline Emotion & $37.9(6.9)$ & $36.2(9.6)$ & $\begin{array}{l}1.1 \\
(-1.2 \text { to } 3.5)\end{array}$ & $\begin{array}{l}-1.3 \\
(-4.3 \text { to } 1.8)\end{array}$ & $\begin{array}{l}2.4 \\
(-1.3 \text { to } 6.0)\end{array}$ & $\begin{array}{l}-1.9 \\
(-5.3 \text { to } 1.4)\end{array}$ & $\begin{array}{l}-0.6 \\
(-3.4 \text { to } 2.2)\end{array}$ & $\begin{array}{l}-1.3 \\
(-5.7 \text { to } 3.1)\end{array}$ \\
\hline Fatigue & $20.7(3.6)$ & $19.3(5.6)$ & $\begin{array}{l}-1.6 \\
(-3.2 \text { to } 0)\end{array}$ & $\begin{array}{l}-1.8 \\
(-3.7 \text { to } 0.2)\end{array}$ & $\begin{array}{l}0.2 \\
(-2.2 \text { to } 2.6)\end{array}$ & $\begin{array}{l}-3.0 \\
(-4.9 \text { to }-1.2)\end{array}$ & $\begin{array}{l}-1.4 \\
(-3.1 \text { to } 0.3)\end{array}$ & $\begin{array}{l}-1.6 \\
(-4.1 \text { to } 0.9)\end{array}$ \\
\hline Mastery & $21.4(4.2)$ & $21.7(5.8)$ & $\begin{array}{l}0.5 \\
(-1.1 \text { to } 2.1)\end{array}$ & $\begin{array}{l}-1.4 \\
(-3.2 \text { to } 0.3)\end{array}$ & $\begin{array}{l}1.9 \\
(-0.4 \text { to } 4.2)\end{array}$ & $\begin{array}{l}-0.5 \\
(-2.4 \text { to } 1.4)\end{array}$ & $\begin{array}{l}-1.3 \\
(-3.0 \text { to } 0.5)\end{array}$ & $\begin{array}{l}0.8 \\
(-1.8 \text { to } 3.4)\end{array}$ \\
\hline
\end{tabular}

$\star$ Values presented are the mean and SD in parentheses.

tValues presented are the mean and the $95 \% \mathrm{CI}$ in parentheses.

$\ddagger$ Values presented are the maximum distance that the patient can walk in $6 \mathrm{~min}$.

§Dyspnoea was assessed immediately after the 6-min walking test using a 10-cm VAS anchored by the terms "extremely short of breath" (a score of 0 ) and "no shortness of breath" (a score of 10).

\| Scores for quality of life are from worst to best: dyspnoea, 5 to 35 ; fatigue, 4 to 28 ; emotion, 7 to 49 ; mastery, 4 to 28 . 
RESPONSE TO INHALED CORTICOSTEROIDS Changes in $\mathrm{FEV}_{1}$ are shown in table 4 and no difference between the two groups was seen at three or six months. The proportion of patients with a $15 \%$ improvement or more in $\mathrm{FEV}_{1}$ was no higher in the budesonide group than in the placebo group at any visit. A comparison of secondary outcomes (exercise capacity, dyspnoea after exercise, and quality of life) is shown in table 5; they were found not to differ between the treatment groups. For the diary data variables, symptom scores (breath, chest, cough, sum of symptoms) with budesonide did not produce a significant improvement compared with placebo. Morning PEFR increased more from baseline in the budesonide group than in the placebo group, but this was observed after only four weeks of treatment and the difference was no longer apparent after one month of treatment.

Both treatments were well tolerated; $59 \%$ of the patients in the budesonide group reported at least one adverse event, and $70 \%$ in the placebo group. Of the adverse events reported, $26 \%$ of those in the budesonide group and $38 \%$ in the placebo group were classified as respiratory in origin. The two most frequently reported adverse events were flu-like disorder and respiratory infection. One exacerbation of COPD caused a patient in the placebo group to discontinue his participation in the study. Four patients in the placebo group and two in the budesonide group required the use of oral steroids for exacerbations of COPD.

\section{Discussion}

Our results suggest that treatment with a high dose inhaled corticosteroid for a period of at least six months fails to improve lung function in most patients with stable but advanced COPD already on bronchodilator therapy who have not improved with oral prednisone. Assessment of other outcome parametersincluding daily symptoms, exercise capacity, and quality of life-leads to the same conclusion.

We made a concerted attempt in designing this trial to select patients with COPD and not asthma. Selection criteria were chosen so that results could best be applied to patients with moderate to severe disease, the patients most often seen in clinical practice. Excluding asthmatic patients is important because these patients are known to respond to inhaled corticosteroids. A recent Dutch study ${ }^{10}$ on relatively young patients with airways obstruction, comprising both asthma and COPD, has clearly shown that the response to inhaled corticosteroids was confined largely to the asthmatic group. Another study suggesting a positive response to inhaled corticosteroids ${ }^{11}$ selected young patients with preclinical COPD. In these studies the patients selected were not therefore representative of COPD patients who come to medical attention because of symptomatic airflow obstruction.

The treatment groups were similar with respect to demographic characteristics, smoking history, medication at entry, and severity of lung disease. Therapeutic interventions other than the one being studied were distributed equally in the two treatment groups. Important co-interventions were the use of bronchodilators. The use of different bronchodilator co-therapies was similar in the two groups at entry. Efforts were made to ensure that the bronchodilators in each treatment group during the study were taken as usual, administered properly, and withheld prior to each visit when possible. To assure that outcomes were measured similarly in the treatment groups, the patients and the investigators were blinded to the study treatment.

The absence of a treatment effect is unlikely to be due to insufficient dose, insufficient duration, or inadequate drug delivery. There are no clear guidelines concerning the minimal effective dose. However, the doses used in this study were above the standard dose used in clinical practice for patients with asthma and COPD. The duration of at least six months was most likely to determine the effect of inhaled corticosteroids on physiological and functional parameters. Effects are demonstrable in asthma within two weeks and most of the improvement in lung function is observed within 3-6 months. The study was not designed to assess the effect of inhaled corticosteroids on the annual decline in lung function. This question is presently under investigation in Europe and in the USA. Inadequate inhalation technique may be another cause of a poor response. We deliberately administered high doses of inhaled corticosteroid to ensure adequate inhalation and we checked and corrected the inhalation technique at each visit.

Poor adherence to the study medication did not appear to be a problem but was only self reported in the daily diary. The withdrawal rate was not unexpectedly high for a trial in elderly patients with advanced COPD. In addition, the most frequent reasons for withdrawal did not appear to be related to treatment response.

The number of patients was sufficient to make chance an unlikely explanation for the results observed. At three and six months the trial had $80 \%$ and $77 \%$ statistical power to detect an estimated $\mathrm{FEV}_{1}$ improvement of $200 \mathrm{ml}$ in COPD patients with a mean (SD) baseline $\mathrm{FEV}_{1}$ of $0.95(0.32) 1$ at the $5 \%$ level of significance.

The study tried to assess not only the physiological benefits, but also the functional benefits of inhaled corticosteroids, exercise capacity, dyspnoea on exertion, and quality of life. The walking test data are limited as an appropriate number of practice walks was not conducted at each visit. There are no data as to the extent to which prior practice walks are needed when the tests are separated at this distance. Likewise, end of exercise breathlessness is difficult to interpret without relating it to starting levels of breathlessness. In chronic lung disease determination of the impact of a treatment requires a measure of how the patient feels. In the present study the size of the treatment effects on quality of life was usually important $^{2021}$ but the confidence interval 
includes the mean of the null hypothesis, which is equivalent to not respecting the null hypothesis.

The results of our study may not be unexpected, given the presence of severe fixed airflow obstruction. However, such patients with moderate to severe COPD are receiving inhaled corticosteroids in growing numbers. ${ }^{22}$

In summary, this study was designed to document the improvement rather than the decline in lung function in patients with severe COPD not responsive to a short course of oral steroids. On the present evidence inhaled corticosteroids, even in "high" doses, are of no physiological or functional benefit to these patients. There therefore appears to be little justification for their use in such patients.

We are indebted to Monica Krusky for her work as research assistant, Chantal Guimont for the statistical analysis, Céline Valin and Sylvie Ouimet for secretarial assistance, and Pierre Ernst for help in revision of the manuscript. Their contribution is gratefully acknowledged.

This study was supported by a grant from Astra Pharma Inc, Canada. Jean Bourbeau was supported by a Chercheur-Boursier Clinicien award from the Fond du Recherche en Santé du Québec (FRSQ)

1 Callahan CM, Dittus RS, Katz BP. Oral corticosteroid therapy for patients with stable chronic obstructive pulmo-
nary disease. A meta-analysis (see comments). Ann Intern nary disease. A meta-a

2 Shim CS, Williams Jr MH. Aerosol beclomethasone in patients with steroid-responsive chronic obstructive pulmonary disease. Am F Med 1985;78:655-8.

3 Bourbeau JR, Rouleau M, Boucher S, Krusky M. A double blind randomized study of inhaled budesonide in patient with steroid-responsive COPD. Am Rev Respir Dis 1993; 147:A317.

4 Robertson AS, Gove RI, Wieland GA, et al. A double-blind comparison of oral prednisolone $40 \mathrm{mg}$ /day with inhaled beclomethasone dipropionate $1500 \mu \mathrm{g} / \mathrm{day}$ in patients with adult onset chronic obstructive airways disease. Eur F Respir Dis 1986;69:65-9.

5 Overbeek SE, Hilvering C, Bogaard JM, et al. A comparison of the efficacy of high dose and normal dose budesonide in prednisone dependent patients with chronic obstructive prednisone dependent patients with chronic obstructi
lung disease (COLD). Eur f Respir Dis 1986;69:581-4. 6 Wardman AG, Simpson FG, Knox AJ, et al. The use of high
dose inhaled beclomethasone dipropionate as a means of dose inhaled beclomethasone dipropionate as a means of assessing steroid responsiveness in obst
ease. $B r \mathcal{F}$ Dis Chest 1988;82:168-71.

7 Hall TG, Kasik JE, Bedell GN, et al. The efficacy of inhaled beclomethasone in chronic obstructive airway disease. Pharmacotherapy 1989;9:232-9.

8 Weir DC, Burge PS. Effects of high dose inhaled beclomethasone dipropionate, 750 micrograms and 1500 micrograms twice daily, and $40 \mathrm{mg}$ per day oral prednisolone on lung function, symptoms, and bronchial hyperresponsiveness in patients with non-asthmatic chronic airflow obstruction. Thorax 1993;48:309-16.

9 Auffarth B, Postma DS, de Monchy JG, et al. Effects of inhaled budesonide on spirometric values, reversibility, airway responsiveness, and cough threshold in smokers with chronic obstructive lung disease. Thorax 1991;46:372-7.

10 Kerstjens HA, Brand PL, Hughes MD et al. A comparison of bronchodilator therapy with or without inhaled corticosteroid therapy for obstructive airways disease. Dutch Chronic Non-Specific Lung Disease Study Group. $N$ Engl f Med 1993;327(20):1413-9.

11 Thompson AB, Mueller MB, Heires AJ, et al. Aerosolized beclomethasone in chronic bronchitis. Improved pulmonary function and diminished airway inflammation. $\mathrm{Am}$ Rev Respir Dis 1992;146:389-95.

12 Knudson RJ, Lebowitz MD, Holberg CJ, et al. Changes in he normal maximal expiratory flow-volume curve with growth and aging. Am Rev Respir Dis 1983;127:725-34.

13 Osterman JW, Armstrong BG, Ledoux E, et al. Comparison of French and English versions of the American Thoracic Society respiratory questionnaire in a bilingual working population. Int f Epidemiol 1991;20:138-43.

14 Butland RJA, Pang J, Gross ER, et al. Two-, six-, and twelveminute walking tests in respiratory disease. BMf 1982;284: 1607-8.

15 Guyatt GH, Pugsley SO, Sullivan MJ, et al. Effect of encouragement on walking test performance. Thorax 1984; 39:818-22.

16 Guyatt GH, Berman LB, Townsend M, et al. A measure of quality of life for clinical trials in chronic lung disease. Thoax 1987;42:773-8.

17 American Thoracic Society. Standardization of spirometry: 1987 update. Am Rev Respir Dis 1987;136:1285-98.

18 Lebowitz M, Quackenboss J, Camilte A, et al. The epidemiological importance of intra-individual changes in objective pulmonary responses. Eur f Epidemiol 1990;132: 237-74.

19 SAS/STAT, SAS/STAT user's guide, version 6. 1st edition. Cary: SAS Institute, 1990

20 Jaeschke R, Singer J, Guyatt GH. Measurement of health status. Ascertaining the minimal clinically important difference. Control Clin Trials 1989;10:407-15.

21 Lacasse Y, Guyatt GH, Goldstein RS. The components of a respiratory rehabilitation program: a systematic overview. Chest 1997; 111:1077-88.

22 Van Andel AE, Reisner C, Menjoge SS, et al. Analysis of inhaled corticosteroids and oral theophylline use among COPD patients from 1987 to 1996. Am $\mathcal{F}$ Respir Crit Care Med 1997;155:A279. 